\title{
Ecological substantiation of the normalization of the state of the air environment in the uninsulated barn in the hot period
}

\author{
R.V. Mylostyvyi, O.M. Chernenko, O.O. Izhboldina, A.M. Puhach, O.S. Orishchuk, O.V. Khmeleva \\ Dnipro State Agrarian and Economic University, 25, S. Efremov Str., Dnipro, 49600, Ukraine \\ E-mail: mylostyvyi.r.v@dsau.dp.ua
}

Received: 21.08.2019. Accepted: 24.09.2019

\begin{abstract}
The results of the assessment of the temperature-humidity regime in the modern uninsulated barn in the summer period with external temperature fluctuations from $+16.6^{\circ} \mathrm{C}$ to $+37.2^{\circ} \mathrm{C}$ are presented. It was established that the indoor climate was significantly related to the state of the environment $(r=0.95 ; p<0.001)$. Significant differences were found in terms of the temperature-humidity index (1.6-5.1 units) in different parts of the building, which may affect the state of comfort of the animals. The use of additional (except natural) ventilation in order to normalize the air environment should be carried out taking into account the time of day and the area of the room.
\end{abstract}

Keywords: Temperature; Relative humidity; Temperature-humidity index; Microclimate; Cow comfort

\section{Introduction}

The combination of physical, chemical and biological environmental factors can affect animals both positively and negatively. If external factors in the form of weather phenomena are uncontrollable, but predictable, then internal factors can be controlled, creating favorable living conditions for animals (Timoshenko et al., 2017). Temperature, humidity, air velocity and room illumination have the greatest influence on the milk productivity and physiological state of cows (Ilin, \& Vtoryiy, 2017; Yano et al., 2018; Hempel et al., 2019; Mylostyvyi \& Chernenko, 2019). The content of carbon dioxide, ammonia, hydrogen sulfide, and more recently methane as a greenhouse gas, is also subject to control (Poteko et al., 2019; Sanchis et al., 2019).

The farm structures of lightweight construction (or uninsulated) are considered the most acceptable in terms of both milk production and cow health (Teye et al., 2007; Trofimov et al., 2014). Compared with capital buildings, the concentration of harmful gases is lower in them and there are the more comfortable conditions for animals to stay (Loshkarev et al, 2018; Jovovic et al., 2019). Due to the use of lightweight enclosing structures and modern systems of natural ventilation, the cost of one place for growing cattle is lower by $24-28 \%$ (Gorbachev, 2010), but the cost of the milking and other technological equipment increases construction costs by a third. In addition, the concept of lightweight construction is economically beneficial only for large dairy enterprises with a population of more than 300 milk cows (Teye et al., 2007).

The problem of ensuring an optimal microclimate in modern farm buildings is also far from being solved. Due to the large dimensions, the ventilation systems provided for in them through side curtains and light and aeration lanterns are able to provide the necessary parameters of the air environment only in a narrow range of external temperatures (Fedorenko et al., 2010; Wang et al., 2018a). In addition, their distribution is unevenly in area and height of buildings. In one zone, the temperature can meet the standards, in the other there is none (Herbut, 2013; Ortiz et al., 2015). Problems in the functionality of such buildings usually occur in winter at temperatures below $-15^{\circ} \mathrm{C}$, when manure passages begin to freeze (Teye et al., 2007), and during the summer heat, when the air warms up to $+36^{\circ} \mathrm{C}$, in the resting place of animals, it rises to $+34^{\circ} \mathrm{C}$ (Voloshchuk \& Khotsenko, 2017).

The reason for the blunders is the active introduction of new foreign technologies and equipment without taking into account the climatic features of the region, which leads to unforeseen deviations of the actual parameters of the air environment from the calculated ones and unreasonable use of the capacities of ventilation systems. Large-capacity buildings put forward additional requirements for microclimate support systems and require new approaches to its assessment and normalization (Vtoryiy et al., 2018).

Among current trends in the development of microclimatic equipment (Ilin \& Vtoryiy, 2017), automatically controlled processes for maintaining a microclimate depending on the time of day and day of the week, intermittent heating (cooling) and ventilation of rooms deserve attention, the operation of which is based on numerous simultaneous studies of the parameters of the air environment inside and outside. Having a great theoretical value for the further construction of mathematical models and being applied due to the effective use of ventilation equipment, such studies require considerable time and effort and are particularly valuable in a particular facility, given the possibility of further implementation of their results in production. 
The aim of the work was to investigate the parameters of temperature and relative humidity of air in the barn, depending on their state in the external environment that is necessary for further effective normalization of the microclimate. Given the design features of an uninsulated building, we believed that we should expect an uneven distribution of temperatures and humidity in the barn. This requires a differentiated approach to ensure their optimal indicators.

\section{Material and methods}

The work was performed in the LLC MVK "Ekaterinoslavskiy" of the Dnepropetrovsk region (48 $\left.34^{\prime} 03.1^{\prime \prime} \mathrm{N}, 34^{\circ} 54^{\prime} 47.0^{\prime \prime} \mathrm{E}\right)$, which is a high-tech innovative dairy complex for the maintenance of Schwyz breed. Cows are situated in modern buildings designed for 600 head of dairy herd (Figure 1). The buildings are located longitudinally in the direction from northeast to southwest relative to the cardinal points. Each of them provides for a two-row placement of cubicles $(1.2 \mathrm{~m} \times 2.5 \mathrm{~m}$ ) in four sections (150 heads each). Special rubber mattresses create comfortable conditions for rest in cubicles. The dimensions of buildings in the axes are $240.0 \mathrm{~m} \times$ $32.4 \mathrm{~m}$. The side walls with a height of $3.0 \mathrm{~m}$ have an armoured concrete base (height $0.4 \mathrm{~m}$ ) with fastening of canvas curtains. Additional day and night (infrared) lighting provides the necessary light conditions in the farm structure. The roof is duplex, made of sandwich panels, which allows maintaining the relative constancy of the temperature in the barn, preventing its excessive overheating or cooling. The height of the room in the roofing ridge is $9 \mathrm{~m}$. In the hot period, to enhance the air exchange, fans of large diameter are included. The storage unit of the milking hall of the company DeLaval, with the herd monitoring system "Dairy Comp-350" (parallel type $2 \times 20$ ) also has an irrigation system. A common mixed ration, balanced in accordance with the "Nutrient Requirements of Dairy Cattle" (2001) feeding standards, is distributed to the feed tables. Balancing diets and selecting the components of the feed mixture depending on the body weight and the productivity of the cows is carried out in collaboration with representatives of Company Cargill (Cargill AT, LLC). Each process section is equipped with separate feeders with salt, chalk and soda, which allows animals to freely consume them as needed. In the interstitial passages there are group car drinkers with heated water in winter. Manure from the access passages is removed with a mobile device (Bobcat S250) when the animals are in the milking parlor.

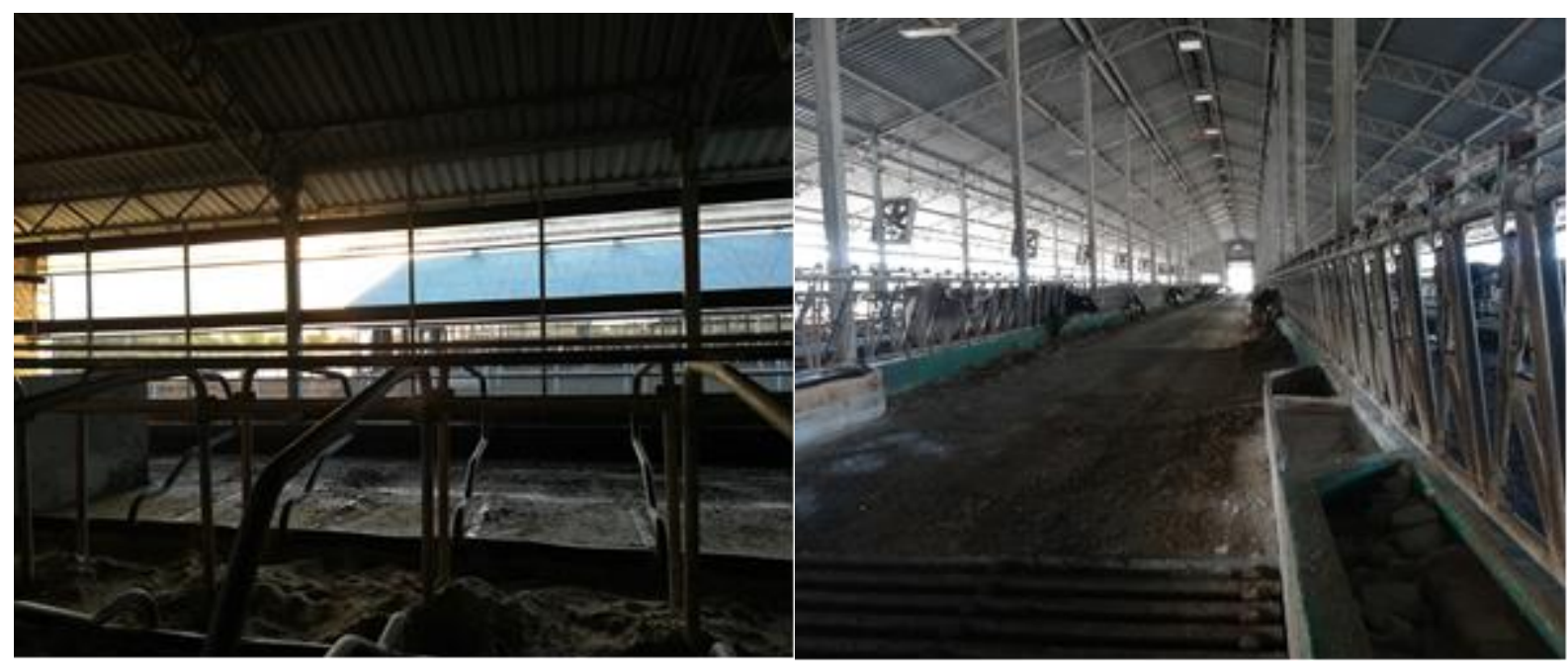

Figure 1. The housing of a lightweight construction for 600 milk cows: a) internal view of cow building from the side of the feeding table; b) boxes for resting cows.

Studies were conducted in summer during the longest light period of the year (June 22-23, 2018). The temperature and humidity conditions in the farm structure and the environment were assessed using an Ambient Weather WS-10 thermohygrometer (Ambient LLC, USA) for more than 30 hours continuously, with sensors recorded every 5-20 minutes. The side curtains in the room were constantly open. Its ventilation occurred naturally (powerful fans did not work). Remote sensors (F007TH) were placed at the level of animal rest directly between the first and second boxes on the side of the end sections (from the southeast and northwest sides) and in the central part as well (between 1st and 2nd boxes), only distantly from the interstitial passage with a group drinking bowl. Protective covers for sensors in the form of durable metal grid were fixed in cubicles in advance so that animals could get used to them. The WS-10 thermo-hygrometer panel was placed outside in a shade (Figure 2). Before operation, the sensors and thermohygrometer were adjusted using an Assman aspiration psychrometer in accordance with GOST 6353-52. During the observations, the temperature fluctuations of the outside air were fixed in the range from $+16.6^{\circ} \mathrm{C}$ to $+37.2^{\circ} \mathrm{C}$, and relative humidity - from $19 \%$ to $81 \%$. 

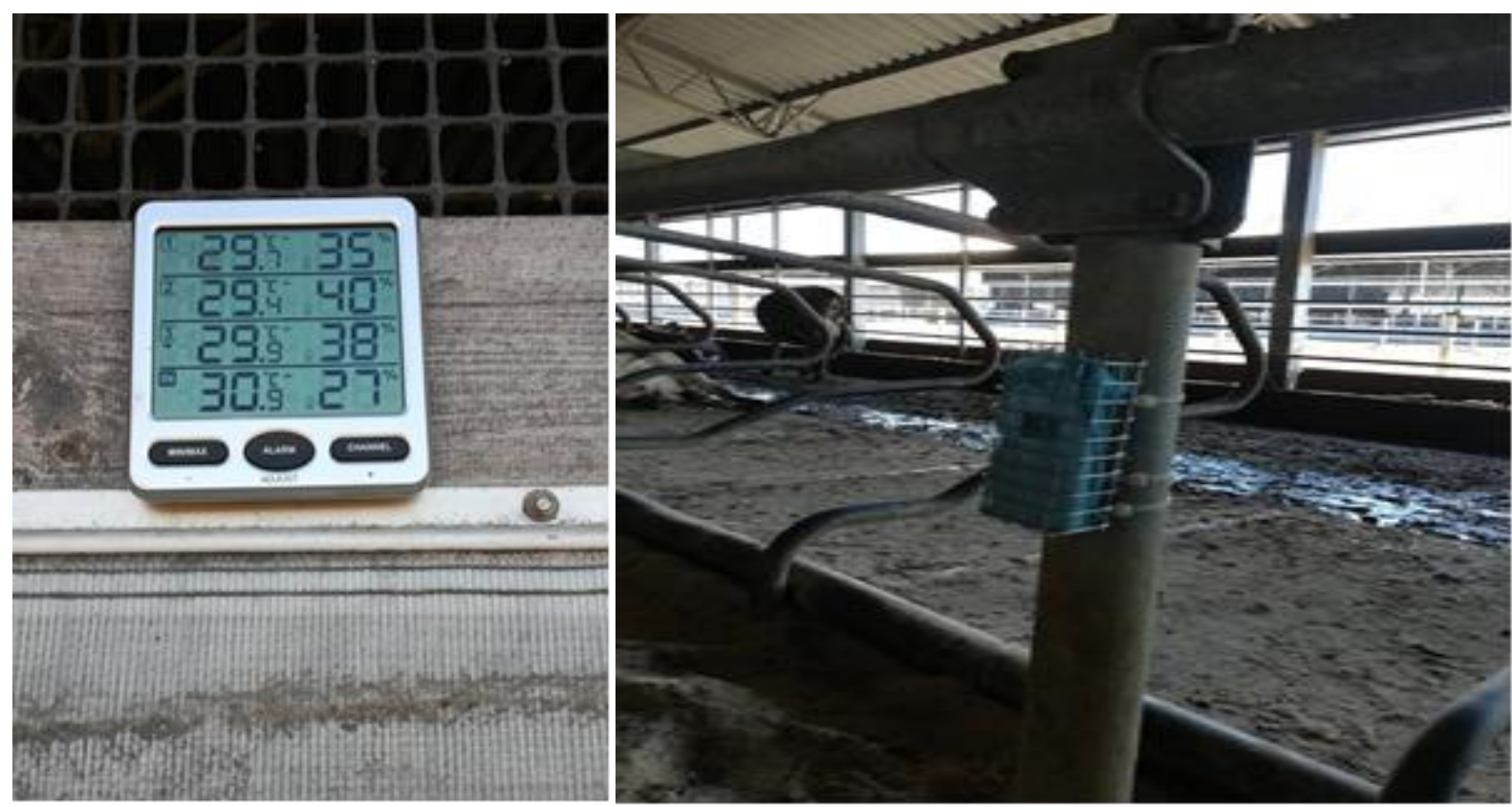

Figure 2. Measurement of temperature and humidity conditions in the uninsulated barn: one of the sensors (F007TH) is located in the cubicle for resting cows (a), the Ambient Weather WS-10 thermohygrometer is located outside the barn (b).

The comfort state of the cows was determined by calculating the temperature-humidity index (THI) by the equation:

$$
\mathrm{THI}=1.8 \times \mathrm{T}-(1-\mathrm{RH} / 100) \times(\mathrm{T}-14.3)+32
$$

Where $\mathrm{THI}$ is the temperature-humidity index, $\mathrm{T}$ is the ambient air temperature, ${ }^{\circ} \mathrm{C}, \mathrm{RH}$ is the relative air humidity, $\%$.

Mathematical processing of the obtained results was performed using the "STATISTICA 10" software package for statistical analysis (StatSoft, Inc., USA). Differences between samples determined by the Mann-Whitney U-test were considered significant at $\mathrm{P}<0.05$.

\section{Results}

It is established that the air temperature in the building was different from the external environment. In particular, in the evening, night and morning time (from 7:00 pm to 7:00 am) the building was warmer. The difference between the maximum values of the average temperature in the room and outside ranged from $0.3^{\circ} \mathrm{C}$ to $3.7^{\circ} \mathrm{C}$. From 9:00 am and until 7:00 pm the room temperature remained cool $\left(0.2^{\circ} \mathrm{C}-4.0^{\circ} \mathrm{C}\right)$ than outside (when it is quickly heated by the sun). Differences were also found in terms of mean temperatures in different parts of the animal building. In particular (Table 1), during the day in its central part $\left(25.5^{\circ} \mathrm{C}\right.$ ) it was $0.3^{\circ} \mathrm{C}$ and $0.9^{\circ} \mathrm{C}$ cooler than in the southeast and northwest ones. The maximum temperature difference between the individual parts of the room was observed at night (at 2:00 hrs): between central and southeast parts it was $1.1^{\circ} \mathrm{C}$; between central and northwest parts $-3.6^{\circ} \mathrm{C}$, between the southeast and north-west sides $-2.5^{\circ} \mathrm{C}$. And in the hot period of the day (from 11:00 to 16:00) the temperature difference between the individual sections did not exceed $0.8^{\circ} \mathrm{C}$. In general, taking into account the temperature dynamics in the building, it was found that it was warmer for 18 hours (from 4:00 pm to 9:00 am) in the northwest part. The difference between the average temperatures in the housing (at all observation points) and the northwest side was from $0.1^{\circ} \mathrm{C}$ to $2.0^{\circ} \mathrm{C}$. From 10:00 to $15: 00$ in the southeast part, the temperature was slightly higher. It exceeded the average in the building by $0.2^{\circ} \mathrm{C}-0.4^{\circ} \mathrm{C}$. In general, temperature fluctuations in the room took place in the range of $+17.7^{\circ} \mathrm{C}$ to $+34.0^{\circ} \mathrm{C}$ (from southeast side $17.7^{\circ} \mathrm{C}-34.0^{\circ} \mathrm{C}$; in the central part $-18.3^{\circ} \mathrm{C}-33.2^{\circ} \mathrm{C}$; from northwest side $-20.2^{\circ} \mathrm{C}-33.2^{\circ} \mathrm{C}$ ).

Table 1. Dynamics of air temperature $\left({ }^{\circ} \mathrm{C}\right)$ in the uninsulated barn during the day $(\mathrm{n}=162, \bar{X} \pm S E$ ).

\begin{tabular}{|c|c|c|c|c|}
\hline & Outside & Building & & \\
\hline Time of day & In the shade & southeast side 1 & central part 2 & northwest side3 \\
\hline 1:00 & $18.2 \pm 0.08$ & $20.6 \pm 0.13 *(2,3)$ & $19.6 \pm 0.16 *(1,3)$ & $21.9 \pm 0.32 *(1,2)$ \\
\hline $2: 00$ & $17.5 \pm 0.13$ & $19.5 \pm 0.19 *(2,3)$ & $18.4 \pm 0.05 *(1,3)$ & $22.5 \pm 0.36^{*}(1,2)$ \\
\hline $3: 00$ & $16.7 \pm 0.11$ & $18.7 \pm 0.04$ & $18.6 \pm 0.07$ & $20.6 \pm 0.28$ \\
\hline 4:00 & $16.7 \pm 0.14$ & $19.4 \pm 0.71$ & $20.2 \pm 0.92$ & $20.8 \pm 0.21$ \\
\hline $5: 00$ & $17.7 \pm 0.22$ & $20.4 \pm 0.15^{*}(2,3)$ & $21.3 \pm 0.17 *(1)$ & $21.3 \pm 0.09 *(1)$ \\
\hline
\end{tabular}




\begin{tabular}{|c|c|c|c|c|}
\hline $6: 00$ & $19.9 \pm 0.32$ & $20.7 \pm 0.08^{*}$ & $21.3 \pm 0.06^{*}$ & $21.2 \pm 0.08^{*}$ \\
\hline $7: 00$ & $22.9 \pm 0.62$ & $22.9 \pm 0.47$ & $22.5 \pm 0.39$ & $23.5 \pm 0.43$ \\
\hline $8: 00$ & $25.9 \pm 0.27$ & $26.0 \pm 0.39$ & $25.2 \pm 0.36(3)$ & $26.2 \pm 0.29(2)$ \\
\hline 9:00 & $27.6 \pm 0.25$ & $27.8 \pm 0.26(2)$ & $26.9 \pm 0.28^{*}(1)$ & $27.9 \pm 0.35$ \\
\hline $10: 00$ & $29.2 \pm 0.46$ & $29.1 \pm 0.41$ & $28.7 \pm 0.45$ & $28.7 \pm 0.53$ \\
\hline $11: 00$ & $31.3 \pm 0.52$ & $30.9 \pm 0.52$ & $30.5 \pm 0.53$ & $30.1 \pm 0.53$ \\
\hline $12: 00$ & $33.1 \pm 0.60$ & $31.7 \pm 0.56^{*}$ & $31.3 \pm 0.56^{*}$ & $31.5 \pm 0.45^{*}$ \\
\hline $13: 00$ & $33.8 \pm 0.81$ & $31.8 \pm 0.69$ & $31.4 \pm 0.67^{*}$ & $31.5 \pm 0.59 *$ \\
\hline $14: 00$ & $34.3 \pm 0.47$ & $31.3 \pm 0.46^{*}$ & $31.0 \pm 0.41^{*}$ & $31.1 \pm 0.38^{*}$ \\
\hline $15: 00$ & $34.6 \pm 0.62$ & $32.4 \pm 0.70$ & $31.7 \pm 0.66^{*}$ & $32.7 \pm 0.56^{*}$ \\
\hline $16: 00$ & $32.6 \pm 0.23$ & $30.9 \pm 0.29 *(2,3)$ & $30.5 \pm 0.24 *(1,3)$ & $31.3 \pm 0.19 *(1,2)$ \\
\hline $17: 00$ & $31.8 \pm 0.18$ & $30.5 \pm 0.12$ & $30.3 \pm 0.04$ & $31.1 \pm 0.11$ \\
\hline $18: 00$ & $34.3 \pm 1.78$ & $30.1 \pm 0.15$ & $30.2 \pm 0.11$ & $30.7 \pm 0.22$ \\
\hline 19:00 & $30.1 \pm 0.46$ & $29.7 \pm 0.18$ & $30.3 \pm 0.19$ & $31.4 \pm 0.41$ \\
\hline $20: 00$ & $27.4 \pm 0.51$ & $27.9 \pm 0.46(3)$ & $28.1 \pm 0.27(3)$ & $29.6 \pm 0.08 *(1,2)$ \\
\hline $21: 00$ & $24.5 \pm 0.32$ & $25.7 \pm 0.18^{*}(3)$ & $26.2 \pm 0.26^{*}(3)$ & $27.4 \pm 0.42 *(1,2)$ \\
\hline $22: 00$ & $22.3 \pm 0.23$ & $24.3 \pm 0.21 *$ & $24.3 \pm 0.22 *$ & $24.6 \pm 0.31 *$ \\
\hline $23: 00$ & $20.4 \pm 0.28$ & $22.0 \pm 0.26^{*}(3)$ & $21.3 \pm 0.48 *(3)$ & $22.9 \pm 0.27 *(1,2)$ \\
\hline $24: 00$ & $19.1 \pm 0.12$ & $21.3 \pm 0.07 *(2,3)$ & $20.0 \pm 0.19 *(1,3)$ & $22.3 \pm 0.19 *(1,2)$ \\
\hline
\end{tabular}

Note: * - Significant difference $(P<0.05)$ between parameters outside and indoors; $(1),(2),(3)$-a significant difference between the separate parts of the building according to the Mann-Whitney U-test.

Humidity in the uninsulated farm building also differed from the outside air. In particular, from midnight until 7:00 am the relative humidity in the cattle-breeding housing was lower. The difference between its average values in the room and outside was from 0.7 to $6.8 \%$. In the morning (after $8: 00$ ) and by night (24:00) the humidity in the room was $0.2-11.4 \%$ higher. It is established (Table 2 ) that during the day, the average value of the relative humidity (54.2\%) from the northwest side was higher by 1.1 and $2.4 \%$ than in the central and southeast parts. The maximum difference between individual areas of the room in this parameter of the air environment was observed in the evening (from 7:00 pm to 10:00 pm): between the central and southeast parts $-10.6 \%$; between the central and northwest parts $-6.8 \%$, between the southeast and northwest sides $-11.8^{\circ} \mathrm{C}$. In the heat period from $11: 00$ to 16:00, the maximum difference in humidity between the indicated parts of the animal-breeding building was only $5.4 ; 6.7$ and $7.8 \%$. Taking into account the dynamics of relative humidity, it can be argued that for 13 hours of the day (from 8 am to 9 pm, inclusive), the air from the southeast side of the building was drier than in other parts of it. The difference between the average relative humidity in it and separately in the southeast part increased to $6.4 \%$. In general, its value in the air of the farm structure ranged from 27 to $76 \%$ (outside the variation ranged from 19 to $81 \%$ ).

Table 2. Dynamics of relative air humidity in the uninsulated barn during the day ( $\mathrm{n}=162, \bar{X} \pm S E$ ).

\begin{tabular}{lllll}
\hline Time of day & Outside & Building & & \\
In the shade & southeast side 1 & central part 2 & northwest side3 \\
$1: 00$ & $73.1 \pm 0.50$ & $71.1 \pm 0.80(2,3)$ & $68.9 \pm 0.37^{*}(1)$ & $68.3 \pm 0.47^{*}(1)$ \\
$2: 00$ & $74.9 \pm 0.15$ & $70.9 \pm 0.28^{*}(3)$ & $71.1 \pm 0.55^{*}$ & $66.5 \pm 1.08^{*}(1)$ \\
$3: 00$ & $77.7 \pm 0.41$ & $70.1 \pm 0.03$ & $72.7 \pm 0.41$ & $70.6 \pm 1.87$ \\
$4: 00$ & $80.0 \pm 1.41$ & $74.5 \pm 2.12^{*}$ & $74.5 \pm 0.71^{*}$ & $74.5 \pm 0.71^{*}$ \\
$5: 00$ & $78.8 \pm 0.34$ & $74.2 \pm 0.66$ & $75.2 \pm 0.44$ & $73.8 \pm 0.52$ \\
$6: 00$ & $73.6 \pm 1.13$ & $70.3 \pm 0.51^{*}$ & $69.4 \pm 0.46^{*}(3)$ & $71.6 \pm 0.32(2)$ \\
$7: 00$ & $65.3 \pm 2.09$ & $64.3 \pm 1.83$ & $65.8 \pm 1.25$ & $63.8 \pm 2.52$ \\
$8: 00$ & $51.5 \pm 0.97$ & $52.3 \pm 0.92$ & $54.7 \pm 1.32$ & $54.7 \pm 1.15$ \\
$9: 00$ & $44.0 \pm 0.47$ & $47.4 \pm 0.52^{*}$ & $48.3 \pm 0.65^{*}$ & $48.4 \pm 0.78^{*}$ \\
$10: 00$ & $39.6 \pm 0.78$ & $43.9 \pm 1.04^{*}$ & $44.1 \pm 1.13^{*}$ & $43.7 \pm 0.56^{*}$ \\
$11: 00$ & $35.2 \pm 0.75$ & $37.7 \pm 0.82(2,3)$ & $43.1 \pm 2.38^{*}(1,3)$ & $43.4 \pm 0.52^{*}(1,2)$ \\
$12: 00$ & $29.4 \pm 0.64$ & $34.3 \pm 0.56^{*}(3)$ & $35.4 \pm 1.74^{*}(3)$ & $41.3 \pm 0.63^{*}(1,2)$ \\
$13: 00$ & $25.9 \pm 1.01$ & $32.7 \pm 1.37^{*}$ & $35.6 \pm 2.13^{*}$ & $37.1 \pm 1.37^{*}$ \\
$14: 00$ & $23.8 \pm 0.82$ & $31.6 \pm 0.74^{*}(2,3)$ & $35.8 \pm 1.53^{*}(1)$ & $38.2 \pm 0.74^{*}(1)$ \\
$15: 00$ & $23.1 \pm 1.23$ & $30.9 \pm 1.72(3)$ & $32.0 \pm 2.30^{*}(3)$ & $38.7 \pm 1.05^{*}(1 ; 2)$ \\
$16: 00$ & $27.7 \pm 0.91$ & $37.5 \pm 1.81^{*}$ & $39.4 \pm 1.21^{*}(3)$ & $37.9 \pm 0.36^{*}(2)$ \\
$17: 00$ & $30.7 \pm 0.41$ & $36.7 \pm 0.41$ & $40.7 \pm 0.41$ & $39.3 \pm 1.08$ \\
\hline
\end{tabular}




\begin{tabular}{lllll}
\hline $18: 00$ & $34.3 \pm 1.78$ & $38.7 \pm 1.08$ & $42.5 \pm 0.71$ & $44.7 \pm 3.08$ \\
$19: 00$ & $39.0 \pm 1.41$ & $39.7 \pm 0.41$ & $50.3 \pm 2.16$ & $48.3 \pm 0.41$ \\
$20: 00$ & $46.6 \pm 0.84$ & $43.2 \pm 0.55^{*}(2,3)$ & $48.2 \pm 0.42(1,3)$ & $55.3 \pm 2.74^{*}(1,2)$ \\
$21: 00$ & $48.8 \pm 0.47$ & $49.3 \pm 1.12(2,3)$ & $51.8 \pm 0.65^{*}(1,3)$ & $56.4 \pm 0.84^{*}(1,2)$ \\
$22: 00$ & $52.1 \pm 0.44$ & $58.1 \pm 1.50^{*}$ & $55.3 \pm 0.21^{*}$ & $55.6 \pm 0.57^{*}$ \\
$23: 00$ & $57.7 \pm 1.02$ & $63.9 \pm 1.78^{*}(2)$ & $56.9 \pm 0.57(1,3)$ & $65.6 \pm 2.05^{*}(2)$ \\
$24: 00$ & $67.2 \pm 1.59$ & $70.3 \pm 0.23(2,3)$ & $65.2 \pm 1.95(1)$ & $66.7 \pm 0.88(1)$ \\
\hline
\end{tabular}

Note: See table one.

During the day, fluctuations in THI outside the room occurred in the range from 61.4 to 80.6 units. In a uninsulated barn, this figure ranged from 63.7 to 82.8 units. At the same time, the difference between the average value of indoor and outdoor THI was 1.5 units (Table 3). The maximum difference in the magnitude of THI was observed at night and especially in the morning. This figure in the room was higher by 3.2-5.1 units than outside. However, in the period of heat (from 12:00 to 16:00.), the differences in the rates of external and internal air were only 0.1-1.5 units, while the value of THI was the highest outside the building. In building itself, the maximum difference in this indicator between the individual parts of the room during the day was: at night (0:00-2:00)5.1; in the morning (3:00-11:00)-1.7; at the afternoon (12:00-15:00)-1.6 and in the evening (16:00-23:00)-3.2. Although the average value of the index in the southeast, central part and northwest did not differ significantly and was respectively $72.5 \pm 0.96$; $72.4 \pm 1.03$ and $73.9 \pm 0.90$ units. That is, in the northwest part the THI by 1.4-1.5 units was higher than in other parts of the building.

Table 3. Dynamics of the temperature-humidity index in the uninsulated barn during the day (n=162, $\bar{X} \pm S E$ ).

\begin{tabular}{|c|c|c|c|c|}
\hline & Outside & Building & & \\
\hline Time of day & In the shade & southeast side1 & central part 2 & northwest side3 \\
\hline $1: 00$ & $63.7 \pm 0.11$ & $67.3 \pm 0.17 *(2,3)$ & $65.6 \pm 0.25^{*}(1,3)$ & $68.9 \pm 0.49 *(1,2)$ \\
\hline 2:00 & $62.7 \pm 0.22$ & $65.6 \pm 0.28 *(2,3)$ & $63.9 \pm 0.07^{*}(1,3)$ & $69.3 \pm 0.48 *(1,2)$ \\
\hline $3: 00$ & $61.6 \pm 0.15$ & $64.5 \pm 0.04(2,3)$ & $64.3 \pm 0.11(1)$ & $67.2 \pm 0.36(1)$ \\
\hline 4:00 & $61.6 \pm 0.21$ & $65.7 \pm 1.25$ & $66.8 \pm 1.48$ & $67.7 \pm 0.28$ \\
\hline $5: 00$ & $63.2 \pm 0.35$ & $67.1 \pm 0.23 *(2,3)$ & $68.8 \pm 0.27^{*}(1)$ & $68.6 \pm 0.18^{*}(1)$ \\
\hline $6: 00$ & $66.3 \pm 0.44$ & $67.4 \pm 0.09 *(2,3)$ & $68.2 \pm 0.13 *(1)$ & $68.2 \pm 0.12 *(1)$ \\
\hline 7:00 & $70.2 \pm 0.75$ & $70.1 \pm 0.52$ & $69.7 \pm 0.47$ & $70.9 \pm 0.59$ \\
\hline $8: 00$ & $73.0 \pm 0.39$ & $73.2 \pm 0.42$ & $72.4 \pm 0.34(3)$ & $73.8 \pm 0.35(2)$ \\
\hline 9:00 & $74.2 \pm 0.28$ & $75.0 \pm 0.36(2)$ & $73.8 \pm 0.30(1,3)$ & $75.2 \pm 0.42(2)$ \\
\hline $10: 00$ & $75.6 \pm 0.51$ & $76.2 \pm 0.43$ & $75.5 \pm 0.44$ & $75.6 \pm 0.64$ \\
\hline $11: 00$ & $77.3 \pm 0.55$ & $77.2 \pm 0.52$ & $77.7 \pm 0.83$ & $77.1 \pm 0.62$ \\
\hline $12: 00$ & $78.3 \pm 0.64$ & $77.6 \pm 0.59 *(3)$ & $77.3 \pm 0.39(3)$ & $78.6 \pm 0.48(1,2)$ \\
\hline $13: 00$ & $78.3 \pm 0.73$ & $77.4 \pm 0.73$ & $77.4 \pm 0.55$ & $77.9 \pm 0.67$ \\
\hline $14: 00$ & $78.5 \pm 0.35$ & $76.6 \pm 0.39 *(3)$ & $77.2 \pm 0.23^{*}$ & $77.5 \pm 0.37^{*}(1)$ \\
\hline $15: 00$ & $78.7 \pm 0.41$ & $77.8 \pm 0.47^{*}$ & $77.2 \pm 0.36^{*}$ & $78.8 \pm 0.68$ \\
\hline $16: 00$ & $77.5 \pm 0.19$ & $77.2 \pm 0.24$ & $77.1 \pm 0.12(3)$ & $77.8 \pm 0.26(2)$ \\
\hline $17: 00$ & $77.1 \pm 0.23$ & $76.7 \pm 0.08$ & $77.1 \pm 0.11$ & $77.8 \pm 0.29$ \\
\hline $18: 00$ & $77.0 \pm 0.07$ & $76.5 \pm 0.11$ & $77.2 \pm 0.04$ & $78.1 \pm 0.32$ \\
\hline 19:00 & $76.5 \pm 0.32$ & $76.1 \pm 0.15$ & $78.2 \pm 0.58$ & $79.6 \pm 0.45$ \\
\hline 20:00 & $74.3 \pm 0.54$ & $74.5 \pm 0.51(3)$ & $75.4 \pm 0.35(3)$ & $78.4 \pm 0.41 *(1,2)$ \\
\hline 21:00 & $70.9 \pm 0.38$ & $72.5 \pm 0.13 *(3)$ & $73.1 \pm 0.27 *(3)$ & $75.7 \pm 0.67 *(1,2)$ \\
\hline $22: 00$ & $68.3 \pm 0.28$ & $71.6 \pm 0.23 *(2)$ & $70.8 \pm 0.33 *(1)$ & $71.7 \pm 0.42 *$ \\
\hline 23:00 & $66.2 \pm 0.33$ & $68.8 \pm 0.25 *(3)$ & $67.3 \pm 0.62(3)$ & $70.3 \pm 0.48 *(1,2)$ \\
\hline 24:00 & $64.8 \pm 0.11$ & $68.3 \pm 0.12 *(2,3)$ & $66.1 \pm 0.39 *(1,3)$ & $69.5 \pm 0.35 *(1,2)$ \\
\hline
\end{tabular}

Note: See Table 1.

Environmental parameters such as temperature and relative humidity are closely related. The correlation coefficient between them was negative $(r=-0.939 ; P<0.001)$ with a high interdependence $(\mathrm{R} 2=0.88)$. In the air of the building, this relation increased (to $r=-$ $0.972 ; R 2=0.94)$, and therefore it is absolutely obviously that using THI to jointly evaluate their influence on the state of animals is very convenient. In general, the indoor climate was largely related to the state of the environment $(r=0.95 ; R 2=0.90)$. However, the highest correlation between THI of the environment and the value of this indicator indoors was observed on the southeast side $(r=0.98 ; R 2=0.96)$. 


\section{Discussion}

When developing modern climate control systems, the main task is to study the dynamic characteristics of temperature and relative humidity in the barn (Vtoryiy et al., 2018). Such information is needed to create mathematical models that reflect the reaction of animals to the action of environmental factors and are able to independently choose an algorithm for the effective operation of ventilation equipment (Vtoryiy et al., 2016; Wang et al., 2018b; Yi et al., 2019). For a successful process of such modeling, it is necessary to have a sufficient amount of information about the dynamics of the microclimate parameters in lightweight farm structures in different parts of the room for a certain period of time, since they differ significantly and depend on the temperature-humidity state of the external environment. In particular (Sofronov et al., 2016), in the central part of the building the temperature was $2-3^{\circ} \mathrm{C}$ higher than at the faces of the barn. The relative air humidity in this part of the building exceeded the standard value by $7-12 \%$, while at the ends it was within the normal range. The most favorable zone for animal habitat was the zone at the entrance to the building, however, information on the barn location relative to the cardinal points and the windrose is not indicated, and therefore it is difficult to draw conclusions about what factors positively influenced the state of the air environment in it. It is reported (Martyinova \& Yastrebova, 2013), that the "critical points" of the deterioration of the microclimate were the northern and southern sides in the barns during the winter period, and in summer the southern and central ones, but there are no data on the placement of buildings in this publication as well.

We are inclined to believe that the uneven distribution of temperatures and humidity in wide-sized buildings that we found may be related to their design features (Marciniak, 2014). We came to the conclusion (Timoshenko et al., 2017), that in buildings made of sandwich panels reinforced on load-bearing reinforced concrete structures and in buildings made of metal structures with a warmed roof, more comfortable conditions for animals are created than in buildings made of prefabricated semi-frame reinforced concrete structures and metal structures without warming of the roof. In particular (Trofimov et al., 2014), in summer, in the face area of the building with a warmed roof it was $1.6^{\circ} \mathrm{C}\left(+27.5^{\circ} \mathrm{C}\right)$ cooler than in the room without it $\left(+29.1^{\circ} \mathrm{C}\right)$, and the relative humidity was lower by $2,8 \%(50.3 \%)$. In the central part of the building from metal structures with a warmed roof it was $1.6^{\circ} \mathrm{C}$ $\left(+28.3^{\circ} \mathrm{C}\right)$ cooler, and humidity was $4.5 \%$ lower $(50.7 \%)$ than in the building without roof warming $\left(+29.9^{\circ} \mathrm{C}\right.$ and $\left.55.2 \%\right)$. The difference in temperature and relative humidity in some parts of these rooms was $0.8^{\circ} \mathrm{C}$ and $2.1-0.4 \%$, with a higher difference in indicators in the building without a warmed roof. More comfortable conditions of the microclimate in a farm structure with a warmed roof contributed to the fact that cows spent more time in a stall lying (5.3\%).

It is claimed (Fedorenko et al., 2010), that in wide-sized buildings out of the three possible modes of natural convection, the regime of stochastic (turbulent) convection is realized, which is characterized by indiscriminate gas flows with intensive mixing. It is reported (Vtoryiy et al., 2018), that the temperature difference in the lightened animal building and outside was $4.9^{\circ} \mathrm{C}-8.4^{\circ} \mathrm{C}$, and regarding the relative humidity of the air it was $2.5-5.1 \%$. Just as in our study, scientists measured the temperature and humidity of the air in real time using electronic sensors that were situated directly above the animal cubicles at a height of $2.5 \mathrm{~m}$. The location of the recorders above the floor at such a distance was motivated by their inaccessibility to animals and operating staff (they should not interfere with the implementation of technological processes and operations). At the same time, the parameters of external air were fixed at a height of $2 \mathrm{~m}$ above the ground. Such an arrangement of sensors, although it was convenient for data collection, however, did not fully reflect the state of the environment in the place of stay of animals, which directly affects them. We understand that in our case, the animals' stay near the sensors could have influenced their measurements during direct contact (licking, etc.). However, the advanced (for several days) fixing of covers from a metal grid without sensors in the boxes should warn "excessive interest "of cows to the placed equipment. The single data given by the authors (Trofimov et al., 2014; Sofronov et al., 2016; Voloshchuk \& Khotsenko, 2017) on the dynamics of the indicators of temperature and relative humidity in the buildings, without taking into account their integral effect, do not fully reflect the state of comfort of the cows, to evaluate which in hot period the temperature-humidity index is used (Vtoryi et al., 2018; Mijic et al., 2019; Pinto et al., 2019; Mylostyvyi et al., 2019). Researchers believe (Hammami et al., 2013; Herbut et al., 2018) that the index value below 68 corresponds to comfortable conditions for animals and is the limit above which they are prone to heat stress. The THI value at the level of 68-71 corresponds to a slight stress, within 72-79 - to moderate stress, while at 80-89 cows are in a state of severe, and 90-99 very strong (hard) stress. The differences we obtained in the indicators of this index both indoors and outdoors, as well as in individual parts of the barn, can directly affect the animal organism and their productivity, as reported by other researchers. (Bertocchi et al., 2014; Schüller \& Heuwieser, 2016; Mylostyvyi \& Sejian, 2019). Based on the data presented by us, during the day cows that were in the central and southeast parts of the room could experience discomfort for 18 hours, in the northwest part for 22 hours. At the same time, THI indices that corresponded to the stress state of animals outside the room (in the shade) lasted only 16 hours. We associate the revealed differences in the uneven distribution of temperature and humidity in the room with its design features and location relative to the cardinal points. The data obtained indicate the need for additional application of active ventilation, not only during the hot period, but also other hours of the day, depending on the area of the room. 


\section{Conclusion}

The temperature-humidity state in the uninsulated barn was different from the external environment. The difference in average air temperatures in the building and outside during the day was $0.2^{\circ} \mathrm{C}-4.0^{\circ} \mathrm{C}$. Relative air humidity differed by $0.7-6.8 \%$. The distribution of these microclimate parameters in the barn was uneven. Differences in temperature and relative air humidity in its individual parts were $1.1^{\circ} \mathrm{C}-3.6^{\circ} \mathrm{C}$ and $6.8-11.8 \%$. The difference between the average THI value in the room and outside was 1.5 units, with a maximum difference between its individual parts during the day of 1.6-5.1 units. A high correlation was found between the temperature and humidity conditions in the room and its position in the environment $(r=0.95)$. The high coefficient of determination $(R 2=0.90)$ indicates the possibility of using mathematical modeling methods for predicting and normalizing the microclimate in light-weight buildings.

\section{References}

Bertocchi, L., Vitali, A., Lacetera, N., Nardone, A., Varisco, G., \& Bernabucci, U. (2014). Seasonal variations in the composition of Holstein cow's milk and temperature-humidity index relationship. Animal, 8(4), 667-674.

Fedorenko, I.Y.A., Kapustin, N.I., Kapustin, V.N., Byirdin, I.N. (2010). Mathematical modeling of frey (natural) convection in livestock buildings of large capacity. Bulletin of Altai State Agrarian University, 11(73), 66-70.

Gorbachev, M.I. (2010). The economic efficiency of modernization of livestock in the farms of the Moscow region. International Technical and Economic Journal, 1, 15-20.

Hempel, S., Menz, C., Pinto, S., Galán, E., Janke, D., Estellés, F., Amon, T. (2019). Heat stress risk in European dairy cattle husbandry under different climate change scenarios uncertainties and potential impacts. Earth System Dynamics Discussions, 1-38.

Herbut, P. (2013). Temperature, humidity and air movement variations inside a free-stall barn during heavy frost. Annals of Animal Science, 13(3), 587-596.

Herbut, P., Angrecka, S., \& Walczak, J. (2018). Environmental parameters to assessing of heat stress in dairy cattle-a review. International Journal of Biometeorology, 62(12), 2089-2097.

Ilin, R.M., Vtoryiy, S.V. (2017). Justification of the parameters of the microclimate monitoring system in livestock buildings. Technologies and technical means of mechanized production of crop and livestock products, 92, 212-217.

Jovovic, V., Pandurevic, T., Vazi, B., \& Erbez, M. (2019). Microclimate parameters and ventilation inside the barns in the lowland region of Bosnia and Herzegovina. Journal of Animal Science of bih, 1(2).

Loshkarev, I.Y.U., Aberyasev, A.YA., Loshkarev, V.I. (2018). Assessment of the effectiveness of introducing a light aerator into the ventilation system of a barn. Actual problems of the energy sector, 104-105.

Marciniak, A. (2014). The use of temperature-humidity index (thi) to evaluate temperature-humidity conditions in freestall barns. Journal of Central European Agriculture, 15(2), 73-83.

Martyinova, E.N., Yastrebova, E.A. (2013). The area of animals in the building is a factor in influencing milk production. Modern problems of science and education, 3, 421.

Mijic, P., Gantner, V., Vuckovic, G., Bobic, T., Baban, M., Gregic, M., \& Pejic, M. (2019). Production of dairy cows at different environmental climatic parameters. Journal of Animal Science of bih, 1(2).

Mylostyvyi, R. V., \& Sejian, V. (2019). Welfare of dairy cattle in conditions of global climate change. Theoretical and Applied Veterinary Medicine, 7(1), 47-55.

Mylostyvyi, R., \& Chernenko, O. (2019). Correlations between environmental factors and milk production of Holstein cows. Data, 4(3), 103.

Mylostyvyi, R., Chernenko, O., \& Lisna, A. (2019). Prediction of comfort for dairy cows, depending on the state of the environment and the type of barn. Development of Modern Science: The Experience of European Countries and Prospects for Ukraine.

Ortiz, X.A., Smith, J.F., Villar, F., Hall, L., Allen, J., Oddy, A., Collier, R. J. (2015). A comparison of 2 evaporative cooling systems on a commercial dairy farm in Saudi Arabia. Journal of Dairy Science, 98(12), 8710-8722.

Pinto, S., Hoffmann, G., Ammon, C., Amon, B., Heuwieser, W., Halachmi, I., Amon, T. (2019). Influence of barn climate, body postures and milk yield on the respiration rate of dairy cows. Annals of Animal Science, 19(2), 469-481.

Poteko, J., Zähner, M., \& Schrade, S. (2019). Effects of housing system, floor type and temperature on ammonia and methane emissions from dairy farming: A meta-analysis. Biosystems Engineering, 182, 16-28.

Sanchis, E., Calvet, S., Prado, A. del, \& Estellés, F. (2019). A meta-analysis of environmental factor effects on ammonia emissions from dairy cattle houses. Biosystems Engineering, 178, 176-183.

Schüller, L. K., \& Heuwieser, W. (2016). Measurement of heat stress conditions at cow level and comparison to climate conditions at stationary locations inside a dairy barn. Journal of Dairy Research, 83(3), 305-311.

Sofronov, V.G., Danilova, N.I., SHamilov, N.M., Kuznetsova, E.L. (2016). The effect of microclimate on the body and milk productivity of dairy cows. Scientific notes of Kazan State Academy of Veterinary Medicine named after NOT. Bauman, 227(3), 82-85.

Teye, F., Hautala, M., Pastell, M., Praks, J., Veermae, I., Poikalainen, V., Pajumagi, A., Kivinen, T., Ahokas, J. (2007). Microclimate in cowsheds in Finland and Estonia. ISAH-2007 Tartu, Estonia.

Timoshenko, V.N., Muzyika, A.A., Moskalëv, A.A., Kirikovich, S.A., SHmatko, N.N., SHeygratsova, L.N., Puchka, M.P., Timoshenko, M.V. (2017).

The influence of technical and technological solutions on the formation of the habitat of cows in the conditions of farms and complexes. Zootechnical science of Belarus, 52(2), 216-223.

Trofimov, A.F., Timoshenko, V.N., Muzyika, A.A., Moskalev, A.A., Kovalevskiy, I.A., SHeygratsova, L.N. (2014). The formation of a microclimate in livestock buildings of various types for the maintenance of lactating cows. Scientific notes of an educational institution Vitebsk Order Badge of honor State Academy of Veterinary Medicine, 50(2-1), 331-335. 
Voloshchuk, V. M., \& Khotsenko, A. V. (2017). Dynamika temperatury repeaters of the internal elements in the design of the cinnamon frame is of the type behind the diy factoriv of the usual middleware. Visnik Sumskoho National Angarho University, 5(2), 37-41.

Vtoryi, V., Vtoryi, S., \& Ylyin, R. (2018). Investigations of temperature and humidity conditions in barn in winter. Latvia University of Agriculture.

Vtoryiy, V.F., Vtoryiy, S.V., Ilin, R.M. (2018). Model of temperature-humidity regime of a barn depending on environmental parameters. Technologies and technical means of mechanized production of crop and livestock products,96, $203-209$.

Vtoryiy, V.F., Vtoryiy, S.V., Lantsova, E.O. (2016). Graphic information model of the microclimate in the barn. Technology and technical means of mechanized production of crop and livestock products, 89, 183-189.

Wang, X., Zhang, G., \& Choi, C.Y. (2018a). Evaluation of a precision air-supply system in naturally ventilated freestall dairy barns. Biosystems Engineering, 175, 1-15.

Wang, X., Zhang, G., \& Choi, C.Y. (2018b). Effect of airflow speed and direction on convective heat transfer of standing and reclining cows. Biosystems Engineering, 167, 87-98.

Yano, A.A., Adiarto, A., \& Widayati, W. (2018). Application of a tunnel-ventilated barn on the physiological responses, milk yield, and dry matter intake of dairy cows in tropical area during the wet season. Journal of Animal Behaviour and Biometeorology, 6(4), 97-101.

Yi, Q., Li, H., Wang, X., Zong, C., \& Zhang, G. (2019). Numerical investigation on the effects of building configuration on discharge coefficient for a cross-ventilated dairy building model. Biosystems Engineering, 182, 107-122.

Citation: Mylostyvyi, R.V., Chernenko, O.M., Izhboldina, O.O., Puhach, A.M., Orishchuk, O.S., Khmeleva, O.V. (2019). Ecological substantiation of the normalization of the state of the air environment in the uninsulated barn in the hot period. Ukrainian Journal of Ecology, 9(3), 84-91. 